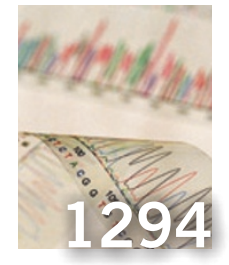

Getting personal:

A new report offers

advice on advancing

personalized medicine

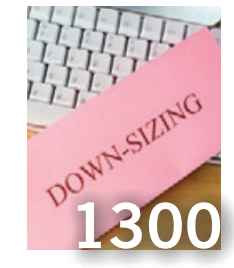

Stock solution:

Biomed companies

cut jobs to cope with

the financial crisis

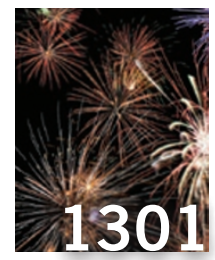

Good-bye, 2008:

Our year-end special

takes a look at the

past year's headlines

\title{
Proposed animal research reforms spark concern in Europe
}

The current EU directive on the use of animals in research is widely viewed as out of date. Nevertheless, proposed reforms to animal research legislation in Europe, released on 5 November, have been greeted with dismay by scientists, who are warning the changes could cripple science. Concerns have focused on the controversial wording of the draft directive, which some say could rule out much research on nonhuman primates.

Both academic societies and industry bodies are demanding changes to the proposed directive released by the European Commission.

"As we look at the small print, we are seeing a ratcheting up of the regulation without commensurate gains in animal welfare," says Simon Festing, executive director of the UK's Research Defence Society, which lobbies in support of animal researchers. He also warns that the revised directive would push projects out of the continent: "without question, if it went through unchanged, it would rapidly accelerate the departure, probably to the Far East, of a great deal of research."

Researchers warn that specific rules, on, for example, the sizes of cages used to house laboratory animals, may cause increases in costs. At the same time, other proposals such as requiring ethical evaluations, although noncontroversial in principle, have raised concerns about additional bureaucracy. Another sticking point is the proposal that the directive be widened to include certain types of invertebrates in its remit, which could further increase costs and administrative burdens for researchers.

For many, though, the nonhuman primate issue is the most troubling. "The thing that most concerns us [...] is the issue of nonhuman primates," says Tony Peatfield, acting director of corporate affairs at the UK's Medical Research Council.

Nancy Lee, a policy advisor at the Wellcome Trust medical charity agrees. She told Nature Medicine, "Our concern at the moment is [the primate rules] would be very limiting for basic research."

The draft directive states that nonhuman primates should not be used in research

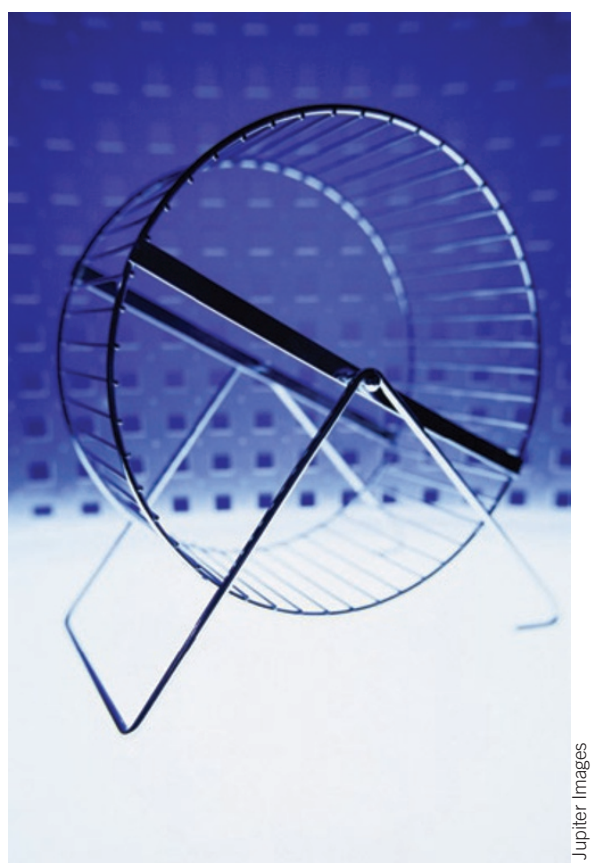

Difficult progress: Rules will add bureaucracy

except for the "preservation of the [nonhuman primate] species" or "with a view to the avoidance, prevention, diagnosis or treatment of life-threatening or debilitating clinical conditions in human beings."

Peatfield notes, "There is a provision in there about basic research, but it is only basic research with that [species preservation or clinical conditions] in mind. If you want to do any other basic research — that would appear to be outlawed."

Specific rules on primate use could also hinder even work allowed within the new regulations. Europe wants to phase out the experimental use of all wild-caught animals and is seeking a move toward using only the offspring of captive-bred animals within seven years of the directive becoming law for some species, including macaques, and ten years for others. It is unclear that suppliers of laboratory primates will be able to meet this deadline, owing to the costs associated with this switch.

Research involving great apes would be totally banned for the first time, although no work on these animals is conducted in Europe at present, and there is an exception in the rule if a pandemic threatens human populations.

\section{Time for change}

The current European directive was produced in 1986 and has been superseded in several EU countries by tougher national legislation, leading to variation in standards. In addition, the European Commission says many of the provisions in the current directive "are open to interpretation, and some are more political than regulatory in nature."

The Commission insists that, where it is not possible to find alternatives to animal testing, either the number of animals used should be cut or the experiments should be made less harmful. "It is absolutely important to steer away from testing on animals," said Europe's environment commissioner Stavros Dimas, when announcing the new proposal.

The draft will now go to the European Parliament, where members must vote on it. At the moment, it is not clear that the current parliament will be able to make this vote before it breaks up next year in preparation for elections in June.

"The process is only really just beginning," says Lee. "What there needs to be more of is scientists and the research community explaining the importance of basic research and the effects some of these provisions would have on basic research."

Festing adds, "Scientists in member states must as a matter of urgency contact their [representatives in the European Parliament]."

However antivivisection groups are also preparing to lobby. The Dr. Hadwen Trust, a UK group that promotes alternatives to animal research, has called the new directive a "once in a lifetime opportunity" for Europe to end animal experiments. "We still think it could go a lot further, and we'll be lobbying for more changes," says Nicky Gordon, a science officer at the trust. "We would like to see phase-out of all primate studies."

Daniel Cressey, London 